
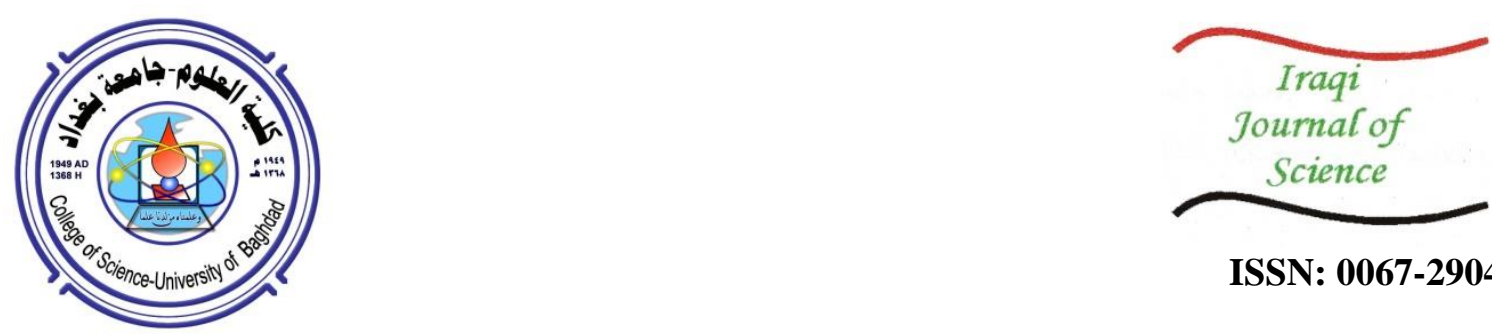

ISSN: 0067-2904

\title{
Thermal Properties of Polyester/Epoxy Blend
}

\author{
Aqeel M. Ali ${ }^{*}$, Mohammed A. Jaber ${ }^{1}$, Nooraldeen A. Toama ${ }^{2}$ \\ ${ }^{1}$ Departmen of Material Science, Polymer Research Center, University of Basrah, Basrah, Ir \\ ${ }^{2}$ Department of Chemistry and polymer Technology, Polymer Research Center, University of Basrah, Basrah
} Iraq

Received: 18/11/2019 Accepted: 24/7/2020

\begin{abstract}
Unsaturated polyester toughened Epoxy was developed. Epoxy resin had toughened by weight fraction of 10, 20,30, and 40 wt. \% unsaturated polyester. FTIR spectroscopy has been used to investigating the intermolecular hydrogen bonding. Unsaturated polyester-epoxy matrices were characterized for their thermal properties. The FTIR test detected a peak shift of the functional groups which can explain cross-linking occurs between the two resins. The crosslinking between epoxy and unsaturated polyester confirmed via the existence of the stretching asymmetrical C-C band and contraction of the C-O band. The DSC test demonstrated that glass transition temperature value decreases with epoxy strengthening. The specific heat capacity and thermal conductivity have been affected the unsaturated polyester percentage. Thermal conductivity, specific heat capacity and thermal effuisivity increased by weight fraction of polyester. The thermal diffusivity values of blends showed a little decreasing.
\end{abstract}

Keywords: Epoxy, Unsaturated polyester, Specific heat, Thermal conductivity, FTIR, Glass transition temperature.

$$
\begin{aligned}
& \text { الخصائص الحرارية لخليط بولي أستر أيبوكسي } \\
& \text { عقيل محسن علي 1*, محمد علي جابر 1, نورالدين عبدالله طعمة2 }
\end{aligned}
$$

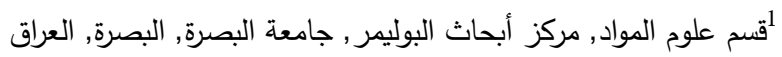

$$
\begin{aligned}
& \text { 2 قسم الكيمياء و تكنولوجيا البوليمرات, مركز أبحاث البوليمر , جامعة البصرة, البصرة البصرة, العراق البراق }
\end{aligned}
$$

تم تحضير خليط بوليمري من مادتي الايبوكسي والبولي استر غير المشبع، حيث أستعمل ألاييوكسي

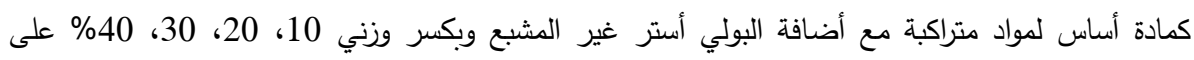

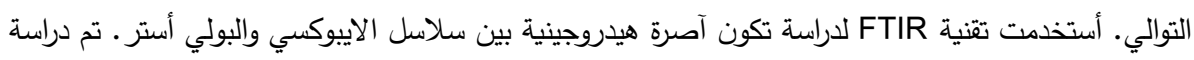

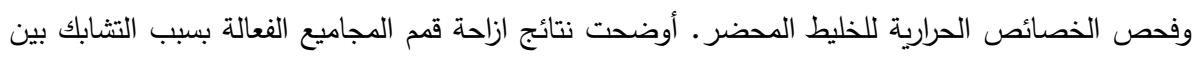

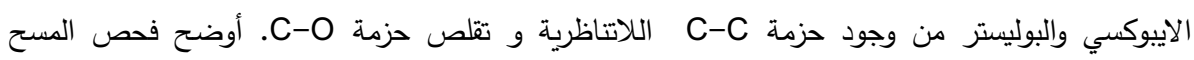

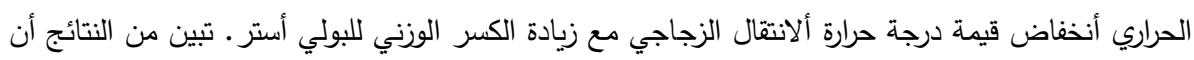

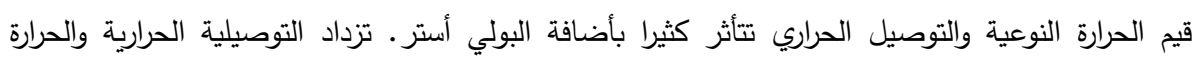

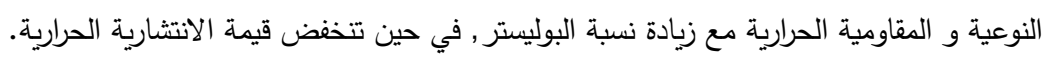




\section{Introduction}

In our daily life, the polymer blends have been one of the primary areas in polymers science and technology over the past several decades [1]. Polymer blends offer versatile industrial applications through property enhancement and economic benefits. Polymer blends are defined as any combination of two or more polymers resulting from common processing step [2]. These blends are used to enhance some thermal, physical and mainly mechanical behavior of polymers [3-7]. The use of polymer alloys and blends have grown so very fast as compared with other polymer materials system; mainly because of their low cost and their acceptable performance. Polymers thermoset commonly used for structural matrix applications as their high; thermal and mechanical properties, excellent bonding with reinforcement, low viscosity, and low cost addition to ease manufacturing. Unsaturated polyester resins (UP) are used widely because of their physical and chemical performance [8-10]. The low viscosity of UP resins in the uncured state is a favorable property due to the resin is processed and controlled with no need to equip of high pressure. Many of techniques to toughness's enhancement are built on the thermosetting polymers such as epoxy [11-14]. However, modification of UP resin with epoxy (EP) improved its mechanical properties with enhancement in the thermal properties. Base on epoxy excellent physical and chemical characteristics, it is an accepted matrix material for preparation of advanced composites that meet daily multipurpose such as missile equipment, computer hardware components, electrical board materials.

The purpose of the present work was to investigate the effects of unsaturated polyester on the solid state thermal properties of epoxy resin. In this project, we have studied the thermal conducting parameter, FTIR spectra and specific heat capacity of different EP/UP blend.

\section{Experimental Procedure}

Epoxy resin (Nitoprime 25 base) supplied by Fosroc international limited company (United Arab Emirates), which selected in this work is a two component, light yellow liquid epoxy system in the form of low viscosity. After adding the hardener to it in a ratio of 3:1, it transforms into a solid state form. Unsaturated polyester resin (Norsodyne H 13271 TA) mixed with a hardener to it in a weight ratio of $(98: 2)$. In order to prepare the polymer blend, the EP mixture mixed with the UP mixture according to the weight part of two component according to Table-1.

Table 1- Component weight ratio of epoxy and unsaturated polyester polymers

\begin{tabular}{|c|c|c|c|c|c|c|c|}
\hline Material & \multicolumn{7}{|c|}{ Component Ratio \% } \\
\hline EP & 100 & 90 & 80 & 70 & 60 & 50 & 0.0 \\
\hline UP & 0.0 & 10 & 20 & 30 & 40 & 50 & 100 \\
\hline
\end{tabular}

Infrared spectra with a FT-IR spectroscopy of the samples were measured (Digital FTS-80, BioRad FT-IR spectrometer). Scan operations using $\mathrm{KBr}$ pellets within the range $\left(400-4000 \mathrm{~cm}^{-1}\right)$ at a 4.0 $\mathrm{cm}^{-1}$ of spectral resolution. Specific heat capacity and temperature of glass transition $(\mathrm{Tg})$ of the samples were determined by using a DSC Shimadzo in the range of temperature $50-150^{\circ} \mathrm{C}$ at $10^{\circ} \mathrm{C} / \mathrm{min}$ heating rate within nitrogen atmosphere. Thermal conductivity $(\mathrm{K})$ measurement has been done by The P.A. Hilton H940 Heat Conduction Unit. K can be calculated using Fourier's law. The equation is given as follows:

$$
K=-\frac{q}{A \Delta T}
$$

Where: K, thermal conductivity $\left(\mathrm{W} /{ }^{\circ} \mathrm{K} . \mathrm{m}\right), q$, Heat energy $(\mathrm{W}), T$, temperature $\left({ }^{\circ} \mathrm{K}\right), x$, thickness of test specimen $(\mathrm{m})$, and $A$, area of test specimen $\left(\mathrm{m}^{2}\right)$. The thermal diffusivity equation $\left(\mathrm{m}^{2} / \mathrm{s}\right)$ is:

$$
D=\frac{K}{C p, p} \ldots \ldots \ldots . .2
$$

Where: $C p$ : specific heat capacity $(\mathrm{J} / \mathrm{km} . \mathrm{k}), \rho$ : density of sample $\left(\mathrm{kg} / \mathrm{m}^{3}\right)$. The effuisivity equation $\left(\mathrm{Ws}^{1 / 2} / \mathrm{m}^{2} \cdot \mathrm{k}\right)$ is:

$$
\epsilon=\sqrt{C p \cdot \rho \cdot K} \ldots \ldots \ldots 3
$$




\section{Results}

\subsection{Fourier Transform-Infrared Spectroscopy (FTIR)}

Figuer-1 shows the FTIR spectra from 500 to $4000 \mathrm{~cm}^{-1}$ of (EP $100 \%$ ), (UP 100\%), and (EP $60 \%$ + UP 40\%) blend systems. Table-2 presents the FTIR peaks for the epoxy, unsaturated polyester and their blend. At around 3,400-3,500 $\mathrm{cm}^{-1}$ the broad peaks indicate the presence of hydroxyl group of epoxy resin, and the peaks in the range of $750-940 \mathrm{~cm}^{-1}$ caused by the asymmetric stretching vibration of epoxide ring. The $940 \mathrm{~cm}^{-1}$ is strongly attributed to the stretching absorption of $\mathrm{C}-\mathrm{O}$ in the epoxide ring. The skeleton formed by chains of EP and UP resins presents the reaction of epoxide ring and the hydroxyl group in the polyester which confirmed to decrease in the intensity of the epoxy band at 940 $\mathrm{cm}^{-1}$. The strong peak of $\mathrm{C}=\mathrm{C}$ stretches occurred at $1608 \mathrm{~cm}^{-1}$ which of the aromatic ring. The shifts in the peaks of the functional groups which can explain cross-linking occurs between the resins. The crosslinking between EP and UP confirmed via the existence of the stretching asymmetrical C-C band and contraction of the $\mathrm{C}-\mathrm{O}$ band. In polyester, the $\mathrm{C}-\mathrm{N}$ band is observed at $1285 \mathrm{~cm}^{-1}$, and as the weight fraction of UP increases, there were band shift observed at $1294 \mathrm{~cm}^{-1}$. This shift is preferred to the asymmetrical -C-O-C- stretching of aryl alkyl ether of epoxy. An asymmetric stretching of methylene occurs at $2929 \mathrm{~cm}^{-1}$, and the peaks at $2965 \mathrm{~cm}^{-1}$ represent the aliphatic $\mathrm{C}-\mathrm{H}$ stretches of epoxy and UP-epoxy resin. A very broad peak occurs at $3,400-3,500 \mathrm{~cm}^{-1}$ caused by hydroxyl functional group which is the source of hydrogen bonds for the blend systems.
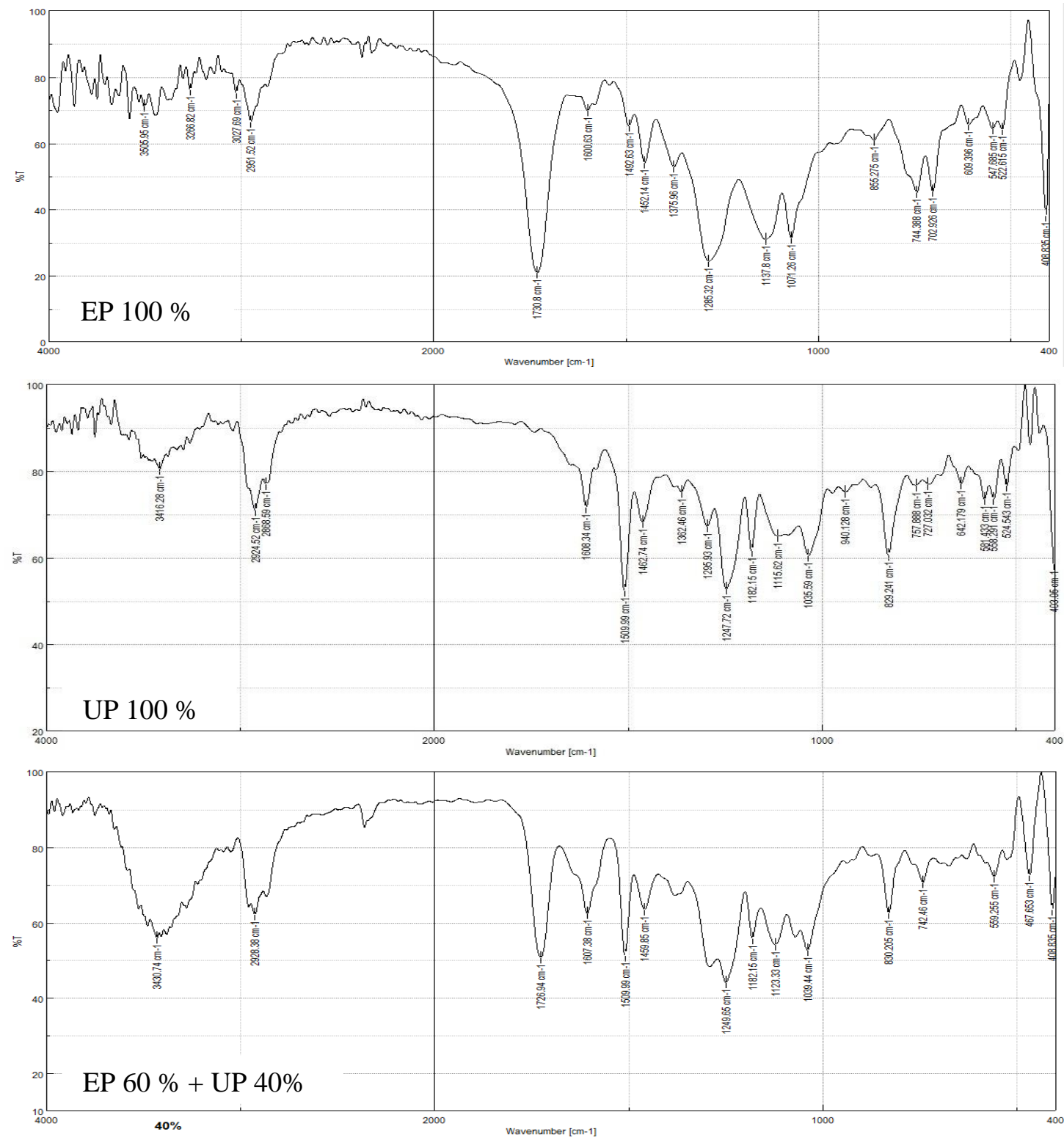

Figure 1- FTIR spectra of (EP $100 \%$ ), (UP 100\%), and (EP $60 \%$ + UP 40\%) blend systems. 
Table 2- The FTIR peaks for the polyester/epoxy blend.

\begin{tabular}{|c|c|c|c|c|c|}
\hline \multirow{2}{*}{ Epoxy } & \multirow{2}{*}{ UP } & \multicolumn{4}{|c|}{ UP wt.\% } \\
\hline & & $10 \%$ & $20 \%$ & $30 \%$ & $40 \%$ \\
\hline 403 & 409 & $406,433,461$ & 416,450 & $416,436,460$ & 408,467 \\
\hline 525 & 523 & 525 & ------------- & 503 & \\
\hline 558 & 548 & 569 & 560 & 558 & 559 \\
\hline 581 & $\begin{array}{c}------------- \\
-\end{array}$ & & -------------- & ---------- & \\
\hline 642 & 609 & 615,661 & 628,668 & ---------- & \\
\hline 727 & 703 & & 720 & 695 & \\
\hline 758 & 744 & 745 & -------------- & 767 & 742 \\
\hline 829 & 855 & 829 & 829,876 & 829 & 830 \\
\hline 940 & ---------------- & 930 & 928 & 934 & \\
\hline 1036 & 1071 & 1038,1076 & 1038 & 1038 & 1039 \\
\hline 1116 & ---------------- & 1115 & 1108 & 1116 & 1123 \\
\hline 1182 & 1138 & 1183 & 1182 & 1182 & 1182 \\
\hline 1248 & --------------- & 1247 & 1249 & 1246 & 1249 \\
\hline 1296 & 1285 & 1295 & 1292 & 1294 & 1296 \\
\hline 1362 & 1376 & 1383 & 1367 & 1363 & 1364 \\
\hline 1463 & 1452 & 1461 & 1463 & 1461 & 1459 \\
\hline 1510 & 1493 & 1510 & 1510 & 1510 & 1510 \\
\hline 1608 & 1601 & 1608 & 1607 & 1607 & 1607 \\
\hline ------------- & 1731 & 1725 & 1730 & 1727 & 1727 \\
\hline 2869 & --------------- & 2862 & 2864 & 2864 & 2864 \\
\hline 2925 & 2956 & 2924 & 2930,2963 & 2926 & 2928 \\
\hline 3025 & 3120,3028 & 3025,3120 & 3120,3059 & 3034,3120 & 3025,3120 \\
\hline 3333 & 3267 & 3333 & 3267,3333 & 3267,3333 & 3267,3333 \\
\hline 3416 & 3506 & 3445 & 3370 & 3381 & 3431 \\
\hline
\end{tabular}

\subsection{Glass transition temperature}

The glass transition temperature $\left(\mathrm{T}_{\mathrm{g}}\right)$ of unmodified Epoxy and epoxy-toughened UP systems are presented in Figure 2. The value of the glass transition temperature of the EP system is decreased, with increasing concentration of UP. This is explained by the chain lengthening and flexibility behaviour of 
polyester resin, which in turn increases the effective crosslinking density and rises the reaction rate and reduces the curing temperature. This rises excess free volume and chain entanglement in the matrix system, leading to a reduction in the values of $T_{g}$, since $T_{g}$ is associated with mobility of the molecule.

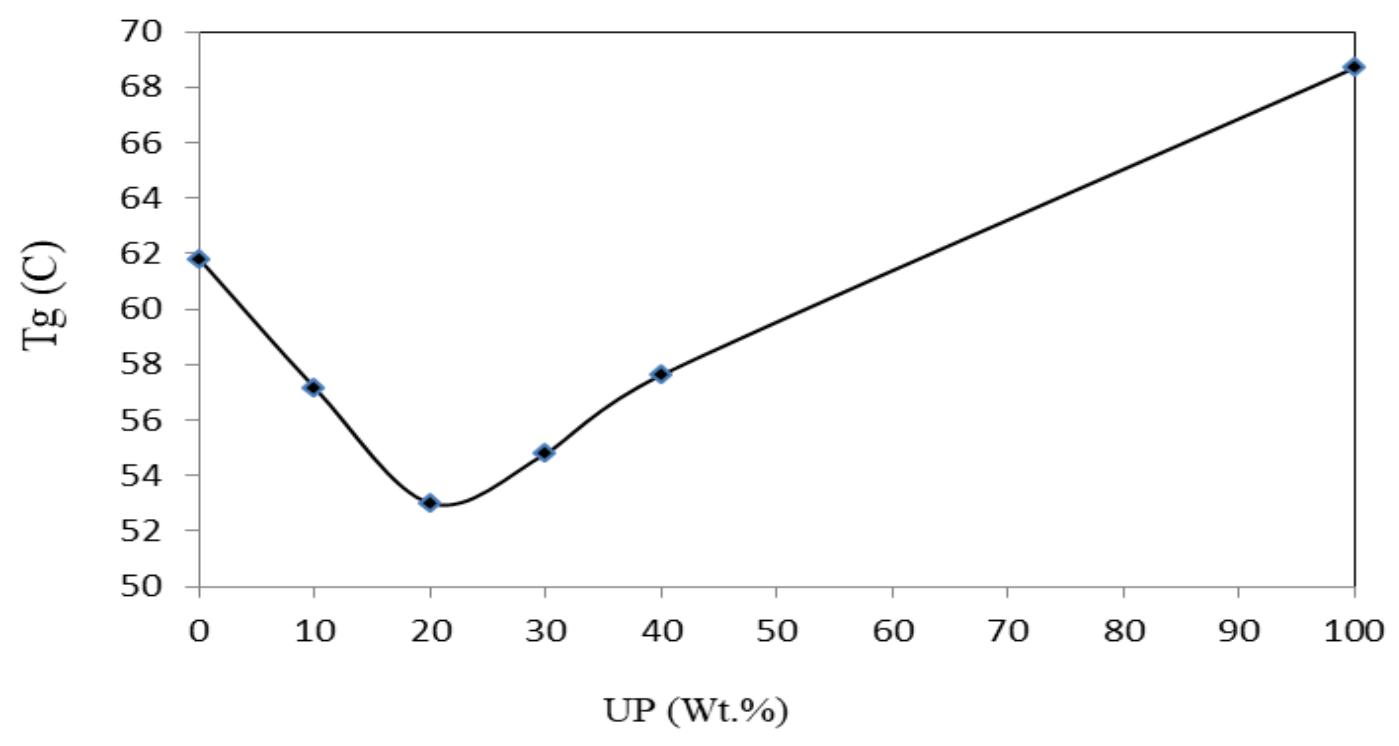

Figure 2- Glass transition temperature of EP/UP blend as a function of UP weight part.

\subsection{Thermal properties}

Thermal properties of the different weight fraction are summarized in Table- 3 showed that the values of thermal conductivity were increased with increasing weight fraction part of UP resin. Thermal conductivity was improved from 0.198 (W/m.k) for epoxy matrix to 0.233 (W/m.k) for $40 \%$ weight part of UP, this may because of good entanglement between the EP and UP polymers of blend due to the miscibility of these two polymers. Thermal conductivity increased with the weight fraction of polyester, this perhaps due to good compatibility between EP and UP in large weight part. Specific heat capacity $(C P)$ results (Figure-3) shown good enhancement as is expected, due to the higher specific heat of the polyester with respect to that of the epoxy polymeric matrix. Thermal diffusivity (D) were decreased with increased weight fractions of UP. The enhancements of thermal conductivity, thermal diffusivity can be explained according to the effect of chain-like structure of UP resin reinforced the EP matrix. Thermal effusivity $(\epsilon)$ were increased with increased weight fractions of UP.

Table 3- Thermal properties of polyester/epoxy blend.

\begin{tabular}{|c|c|c|c|c|c|}
\hline$(\mathrm{EP} / \mathrm{UP})$ & $\rho\left(\mathrm{kg} / \mathrm{m}^{3}\right)$ & $\mathrm{Cp}(\mathrm{KJ} / \mathrm{kg} \cdot \mathrm{K})$ & $\mathrm{K}(\mathrm{W} / \mathrm{m} \cdot \mathrm{K})$ & $\mathrm{D}\left(10^{-7} \mathrm{~m}^{2} / \mathrm{s}\right)$ & $\epsilon\left(\mathrm{W} . \mathrm{s}^{1 / 2} / \mathrm{m}^{2} \cdot \mathrm{K}\right)$ \\
\hline $100 / 0.0$ & 1143 & 1745 & 0.198 & 1.31 & 628 \\
\hline $90 / 10$ & 1165 & 1720 & 0.201 & 1.30 & 634 \\
\hline $80 / 20$ & 1178 & 1830 & 0.204 & 1.27 & 663 \\
\hline $70 / 30$ & 1197 & 1975 & 0.220 & 1.21 & 721 \\
\hline $60 / 40$ & 1203 & 2048 & 0.233 & 1.17 & 757 \\
\hline $0.0 / 100$ & 1255 & 2296 & 0.254 & 1.01 & 855 \\
\hline
\end{tabular}




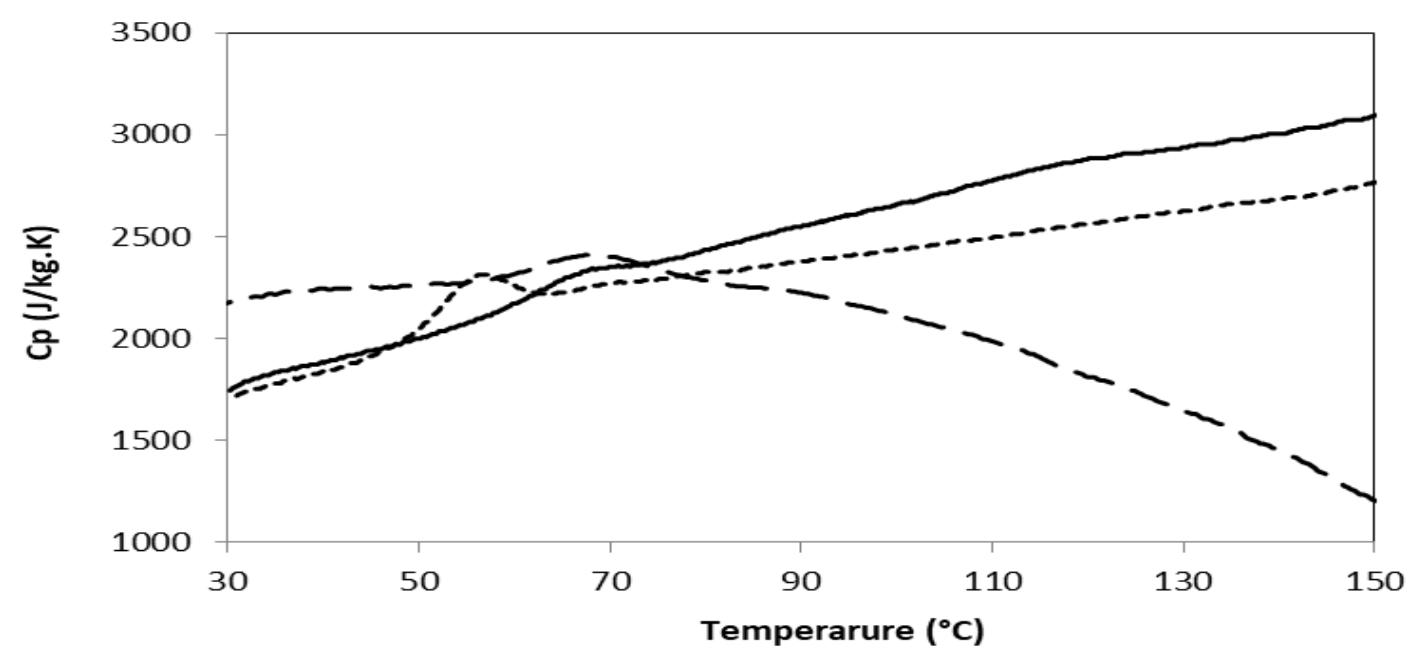

Figure 3- Specific heat capacity of $\mathrm{EP}(ロ$ blend $(\cdots \cdot \cdot)$.

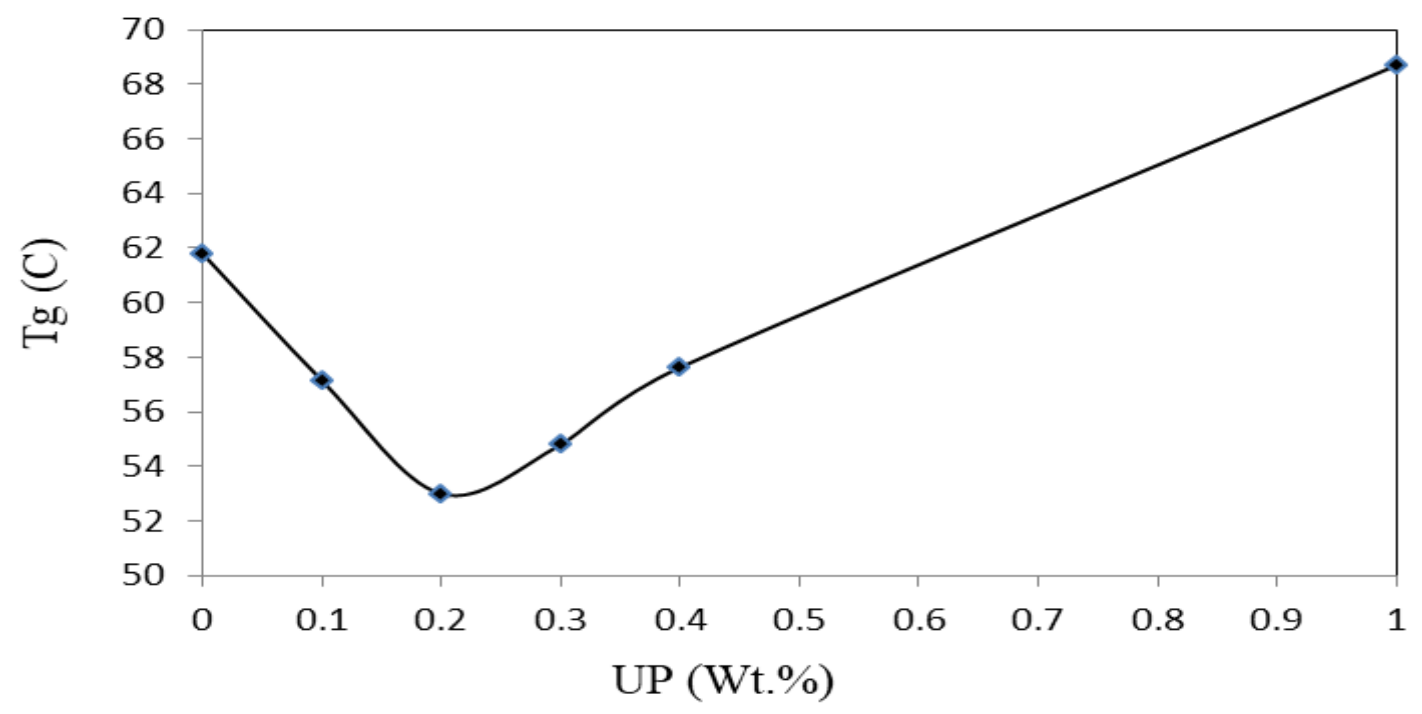

Figure 4- Glass transition temperature of EP/UP blends as a function of UP weight part.

\section{Conclusions}

In the present work polyester/epoxy blends were prepared as a function of polyester weight fraction. The thermal properties of the blends are studied. FTIR results indicated the interchain interaction occurred between polyester and epoxy. DSC results showed that glass transition temperature $\left(\mathrm{T}_{\mathrm{g}}\right)$ was decreased up to $20 \mathrm{wt} \%$ polyester content. A $9^{\circ} \mathrm{C}$ decrease in glass transition temperature was observed for $20 \mathrm{wt}$. \% when compared with pure epoxy. There is an enhancement of the thermal conductivity of epoxy after blending it with UP. Thermal conductivity, heat capacity and thermal effusivity increase with increase weight fraction of polyester values. Thermal diffusivity decreases with increasing weight fraction of polyester. 


\section{References}

1. Benny Cherian A., Alen Varghese L., Thomas Thachil E. 2007. Epoxy-modified, unsaturated polyester hybrid networks. European Polymer Journal, 45:1460-1469.

2. Ali A. M., Al-Mowali A. H. 2014. DFT Study of Poly Furfuryl Alcohol-Rhodamine B Blend. Advances in Chemical Engineering and Science, 4: 161-166.

3. Damodar Reddy A., Deva Kumar M.L.S. 2017. Mechanical Properties of Epoxy / Polyester Blended Composite Using Wollastonite Powder as Filler. International Journal of Recent Innovation in Engineering and Research. 2(10: 11-17.

4. Callister, William D. Jr. and Rethwisch, David G. 2014. Materials Science and Engineering. $9^{\text {th }}$ Edition. New York. John-Wiley and Sons, Inc.

5. Park, S.J., Park, W.B, Lee, J.R. 1999. Roles of Unsaturated Polyester in the Epoxy Matrix System. Polymer Journal, 31(1): 28-31.

6. Liu Y., Zhang W., Zhou H. 2005. Mechanical properties of epoxy resin/hydroxyl-terminated polyester blends:effect of two-phase structure. Polymer International. 54: 1408-1415

7. Mahmood, H. 2016. Effect of Nano SiO2 Particles on Some Physical Properties of (UP/PU) Blend Composite. Eng. And Tech. J. 3: 93-99.

8. Belloa, S., Agunsoyeb, J., Hassana, S., Zebase Kanaa, M., Raheemb, I. 2015. Epoxy Resin Based Composites, Mechanical And Tribological Properties: A Review Tribology In Industry, 37(4): 500524.

9. Mahdi Salih R. 2017. Effect of Water on Some Mechanical Properties of Epoxy Blends Reinforced With Different Weight Fractions of Nano Titanium Oxide and Nano Silica. Iraqi Journal of Science, 58(3C): 1675-1682.

10. Jaafar H. I. , Hussein S.I., Jaafar H. M. 2017. Study of Thermal Conductivity and Solution Absorption for Epoxy-Talc Composites. Journal of Science, 58(4B): 2107-2111.

11. BakarM., R. Duk R., M. Przybylek M., Kostrzewa M. 2009. Mechanical and Thermal Properties of Epoxy Resin Modified with Polyurethane. Journal of Reinforced Plastics and Composites, 28(17): 2107-2118.

12. Buketov A., Brailo M., Yakushchenko S., Sapronova A. 2018. Development of Epoxy-Polyester Composite with Improved Thermophysical Properties for Restoration of Details of Sea and River Transport. Advances in Materials Science and Engineering. https://doi.org/ 10.1155/2018 /63 78782.

13. Kang R., Zhang Z., Guo L., Cui J., Chen Y., Hou X., Wang B., Lin C., Jiang N., Yu J. 2019. Enhanced Thermal Conductivity of Epoxy Composites Filled with 2D Transition Metal Carbides (MXenes) with Ultralow Loading. Scientific Reports, 9: 9135, https://doi.org/10.1038/s41598-01945664-4.

14. Thonon H. H., Hussein N. 2019. Mechanical and Physical Properties of Epoxy and Unsaturated Polyether Complexes Reinforced with Glass Fiber and Nanomaterial Alumina Powder. Journal of Education and Science, 28(1): 273-293. 